\title{
Brain and Central Nervous System Cancer and Benign Brain Tumors Among Chemical Plant Workers in Texas
}

\author{
Salma Haidar, Carol J. Burns, Kay Birdsong, Kenneth Bodner, Eugenio Salazar and \\ James J. Collins*
}

The Dow Chemical Company, Michigan, USA

\begin{abstract}
In the early 1980's, a clustering of brain and central nervous system cancers was observed among workers at a Texas City, Texas chemical plant. A series of studies with follow-up from 1941 to 1983 failed to identify an occupational cause. We added women and newly hired workers to these studies and expanded the follow-up from 1940 to 2001 using a retrospective cohort mortality design. The SMR for brain and central nervous system cancers was slightly less than expected (SMR $=0.93$, 95\% CI 0.60-1.38) whereas the SMR for benign brain tumors was slightly greater than expected $(\mathrm{SMR}=1.50,95 \%$ CI $0.72-2.76)$ during the entire observation period. SMRs were close to expected levels when examining sex, wage type, year of hire, years of latency, and duration of employment for these causes. We observed high rates of brain and central nervous system cancers from 1970 to 1984 but lower rates in the other periods. We conclude that the excess cancer and tumor mortality reported in the earlier studies may be a random cluster and unrelated to workplace exposures.
\end{abstract}

Keywords: Brain cancer, brain tumor, cluster.

\section{INTRODUCTION}

In responding to a complaint in 1978 of brain cancer deaths at a Texas City, Texas Union Carbide Corporation (UCC) chemical plant [1], epidemiologists from UCC and the National Institutes of Occupational Safety and Health (NIOSH) conducted and published three studies that examined central nervous system (CNS) cancer and benign brain tumor mortality among male workers from 1941-1977 at this plant [2-4]. The study groups were drawn from same data sources but varied slightly due to study definitions and eligibility. The findings from these studies led to additional studies of tumors of the brain and CNS at other Texas chemical plants and refineries [5-9].

The UCC study by Austin and Schnatter included 6,588 white males, as shown in Table $\mathbf{1}$, found more observed than expected CNS cancers $(\mathrm{O} / \mathrm{E}=12 / 7.4)$ and all benign brain tumors $(\mathrm{O} / \mathrm{E}=7 / 3.0)$ [2]. Further analyses of the CNS cancers found an increase among hourly employees $(\mathrm{O} / \mathrm{E}=$ 10/5.0). The researchers concluded that there was insufficient evidence to consider the excess occupationally related due to the small number of deaths and lack of a relationship with use of specific chemicals at the site. Similarly, the NIOSH studies of Waxweiler and colleagues also reported more observed than expected deaths for both CNS cancers $(\mathrm{O} / \mathrm{E}=13 / 7.2)$ and benign brain tumors $(\mathrm{O} / \mathrm{E}=6 / 2.4)$ among 7,595 hourly male workers $[3,4]$. When CNS cancers and benign brain tumors were combined, the standardized mortality ratio (SMR) was statistically significant (SMR 1.98 $95 \%$ confidence limits [95\% CI] 1.19 to 3.09 ). Like the UCC study, the investigators could not identify a specific chemical

*Address correspondence to this author at the Dow Chemical Company, 1803 Building, Midland, Michigan 48674, USA; Tel: (989) 636- 1275; Fax: (989) 636- 1875; E-mail: jjcollins@dow.com or other cause for the excess risk of CNS cancers or benign brain tumors. Subsequently, an update of the original UCC study reported no clustering in CNS cancer or benign brain tumor deaths when examining case assignments by work area [10]. The study found no increased mortality among maintenance workers or laborers, in general. The authors speculated that the excess in CNS cancers could be related to an increased likelihood for detection of this cancer in this region, but provide no data to support this statement. Nevertheless, no definitive conclusions were made about the excess in either CNS cancers or benign brain tumors.

We added women to the previous studies and expanded study eligibility and vital status follow-up from January 1, 1940 through December 31, 2001 to further examine the risk of CNS cancer and benign brain tumor deaths at this plant.

\section{MATERIALS AND METHODOLGY}

We identified all past and present full-time employees who worked more than three days at the Texas City plant from January 1, 1940 to December 31, 2001 from payroll and work records. Vital status follow-up was conducted using company files and searches of the US National Death Index (NDI), Social Security Administration, and other sources. Death certificates were obtained whenever possible. All underlying causes of deaths were coded to the International Classification of Disease revision in use at the time of death by a trained nosologist or by NDI Plus which provides coded underlying cause of death. We identified 9,730 employees (8,450 males and 1,280 females) and 3,640 deaths.

We used the OCMAP program to calculate SMRs and 95\% CIs based on cause-specific U.S. rates stratified by sex and race (whites and non-whites) [11]. Subsets of the study group analyzed separately include sex, wage type (hourly and salary), duration of employment $(<1$ year, 1-4 years, 5- 
Table 1. Characteristics of Past Studies and the Current Study at the Union Carbide Plant in Texas City, Texas and Standardized Mortality Ratios (SMR) and 95\% Confidence Intervals (95\% CI) for Selected Causes of Death

\begin{tabular}{|c|c|c|c|c|}
\hline Characteristic & Austin \& Schnatter, 1983 & Waxweiler et al., 1983 & Teta et al., 1991 & Current Study \\
\hline Study Population & White males & Hourly males & Males & Males and females \\
\hline Number of workers & 6,588 & 7,595 & 7,849 & 9,730 \\
\hline Person years & 137,745 & 159,688 & NR & 324,650 \\
\hline Years worked & $1941-1977$ & 1941-1977 & $1941-1983$ & $1940-2001$ \\
\hline Vital status follow-up & $1941-1977$ & $1941-1977$ & 1941-1983 & $1940-2001$ \\
\hline Selected causes of death (ICD 10) & $\begin{array}{c}\text { SMR }(95 \% \text { CI) } \\
\text { [Number of Deaths] }\end{array}$ & $\begin{array}{c}\text { SMR }(95 \% \text { CI) } \\
\text { [Number of Deaths] }\end{array}$ & $\begin{array}{c}\text { SMR }(95 \% \text { CI) } \\
\text { [Number of Deaths] }\end{array}$ & $\begin{array}{c}\text { SMR ( } 95 \% \text { CI) } \\
\text { [Number of Deaths] }\end{array}$ \\
\hline $\begin{array}{l}\text { Brain and Central Nervous System (CNS) } \\
\text { Cancer }(\text { C } 70-72)\end{array}$ & $\begin{array}{c}1.62(0.83-2.83) \\
{[12]}\end{array}$ & $\begin{array}{c}1.81(0.96-3.09) \\
{[13]}\end{array}$ & $\begin{array}{c}1.53(0.89-2.45) \\
{[17]}\end{array}$ & $\begin{array}{c}0.93(0.60-1.38) \\
{[24]}\end{array}$ \\
\hline All Benign Tumors (D10-D36) & $\begin{array}{c}2.35(0.94-4.83) \\
{[7]}\end{array}$ & NR & $\begin{array}{c}2.34(1.17-4.19) \\
{[11]}\end{array}$ & $\begin{array}{c}1.68(1.01-2.63) \\
{[19]}\end{array}$ \\
\hline Benign Brain Tumors (D32-D33, D43) & NR & $\begin{array}{c}2.50(0.88-5.22) \\
{[6]}\end{array}$ & $\begin{array}{c}2.33(0.94-4.81) \\
{[7]}\end{array}$ & $\begin{array}{c}1.50(0.72-2.76) \\
{[10]}\end{array}$ \\
\hline $\begin{array}{l}\text { CNS Cancers \& Benign Brain Tumors com- } \\
\text { bined (C70-C72, D32-D33, D43) }\end{array}$ & NR & $\begin{array}{c}1.98(1.19-3.09) \\
{[19]}\end{array}$ & $\begin{array}{c}1.70(1.09-2.53) \\
{[24]^{*}}\end{array}$ & $\begin{array}{c}1.04(0.72-1.46) \\
{[34]}\end{array}$ \\
\hline
\end{tabular}

$\mathrm{NR}=$ Not reported.

* Calculated by authors.

14 years, and 15+ years), period of hire (before 1950, 19501969, and 1970-2001), and 20 year latency period, defined as years since first hire. Fisher's exact limits were used to calculate $95 \%$ CI for the SMRs.

\section{RESULTS}

We observed 24 deaths due to $\mathrm{CNS}$ cancer $(\mathrm{SMR}=0.93$, $95 \% \mathrm{CI}=0.60-1.38)$ and 10 deaths due to benign brain tumors $(\mathrm{SMR}=1.5,95 \% \mathrm{CI}=0.72-2.75)($ Table 1$)$. The SMR of 1.68 (95\% CI 1.01-2.63) for all benign tumors was statistically significant. When subsets by sex, wage type, duration of employment, period of hire, and latency were examined, none showed more than a small increase in risk and none represented a statistically significant excess. Specifically, more than expected deaths due to CNS cancers were seen only for hourly workers $(\mathrm{SMR}=1.17,95 \% \mathrm{CI}=0.74-1.76)$, workers hired between 1950 and $1969(\mathrm{SMR}=1.15,95 \%$ $\mathrm{CI}=0.60-2.02)$, and those who worked for more than 15 years $(\mathrm{SMR}=1.11,95 \% \mathrm{CI}=0.59-1.90)$. Benign brain tumor deaths were elevated in most subsets, but none was statistically significant. To compare more directly with previous studies, we combined CNS cancers and benign brain tumors producing an SMR of $1.04(95 \% \mathrm{CI}=0.72-1.46)$. Neither the overall SMR for this combined category, nor that of any subset produced more than modest excess in the SMR.

Fig. (1) presents the SMRs cumulated by year of observation for CNS cancers and the benign brain tumors combined. The cumulative SMRs were less than 1.0 before 1960 and greater than 1.0 from 1960-64 onward. However, during the period of 1970 to 1984 , the time of the UCC and NIOSH studies, the cumulative SMRs for CNS cancers and benign brain tumors were significantly greater 1.0. Before and after this period, the cumulative SMRs were compatible with 1.0 including the final observation period where the SMR was 1.04 (95\% CI $0.72-1.46)$ or 34 observed and 32.4 expected.

\section{DISCUSSION}

The studies which have been done on workers at the Texas City site have used death certificates over a period of 60 years to identify CNS cancers or brain tumors. The use of death certificates for diagnosis limits interpretation. First, death certificates usually do not record morphology making it difficult to examine cell types which may be related to specific exposures. Second, not all brain tumors recorded on death certificates are pathologically confirmed when the death certificate is filled out. Thus, metastatic brain tumors are sometimes classified as primary tumors on the death certificate [12]. Third, pathological confirmation also may be more common among workers in industry making it difficult to choose an appropriate comparison group [13]. Finally, the introduction of diagnostic technology by the late 1970's greatly improved the discovery of tumors in brain and aided in the determination of malignant versus benign disease [14].

We found no significant excess in mortality of CNS cancer, benign brain tumors, or the two categories combined in the study group overall or in subsets of workers based on sex, wage type, year of hire, duration of time at the plant, or time since first hire. We identified low SMRs for both CNS cancer and benign brain tumors since 1985 and before 1960 . Conversely, we observed high SMRs between 1970 and 1984 for CNS cancer and benign brain tumors combined. The three previously reported studies were performed concurrent with the 1970 and 1984 "peak" in the cumulative SMR. Since these cancers and tumor deaths were only related to year of observation and not related to sex, wage type, year hired, duration of employment, or latency, and since previous studies at this site found no relationship with exposures and CNS cancer or benign brain tumors, we conclude the findings of previous studies may be the result of chance due to clustering of these deaths in time. 


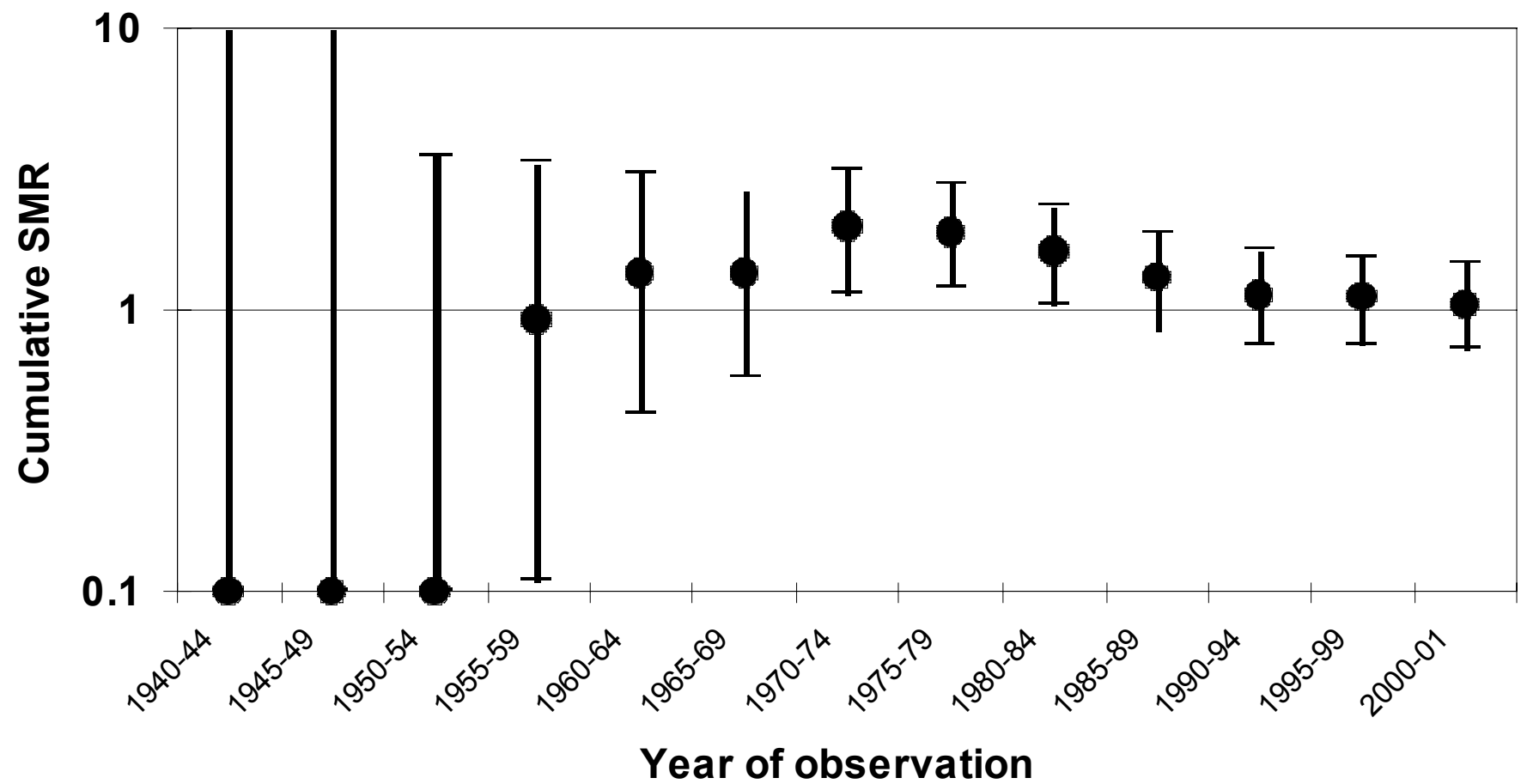

Fig. (1). Cumulative SMRs and 95\% CI for central nervous cancers and benign brain tumors combined from 1940 to 2001 at the Texas City Plant.

Very little is known about the causes of human CNS cancer and benign brain tumors. Other than high exposure to ionizing radiation and trauma, there have been few if any occupational exposures consistently related to increased cancer or tumor rates $[14,15]$. In response to concerns about chemicals causing CNS cancer and benign brain tumors, many studies have been conducted in Texas to examine this relationship, including 39 studies among petroleum refinery and chemical manufacturing workers between 1964-1993 [16]. The findings of these studies were not consistent and never definitive. Mortality from CNS cancer was similar to expected in most refinery and petrochemical companies when compared to the U.S. population. However, a few chemical companies did report observed deaths higher than expected for CNS cancers $[15,16]$. Nevertheless, a specific workplace exposure or production area was not correlated with the cancer rates in these studies. Diagnostic sensitivity bias, misclassification of deaths, and differences in diagnostic procedures have been suggested as possible reasons for these high rates in these chemical companies $[6,16]$.

\section{CONCLUSION}

Previous studies at this plant found high rates of CNS cancers and benign brain tumors in the period before 1984 . These studies examined specific workplace exposures and time in production areas but found no association with cancer or tumor risk. We found rates of CNS cancers and benign brain tumors at expected levels for the entire period of observation for the Texas City plant. The clustering of these deaths in the period between 1970 and 1984 may have given the researchers and the workers at the plant the impression of a chemical cause for these deaths, but we think it more likely that the cluster is a chance occurrence.

\section{ACKNOWLEDGEMENTS}

This research was supported by The Dow Chemical Company. We would like to thank the members of the Epidemiology Group especially Brenda Jammer, and Umang Patel, for data preparation and input. This study conduct was pursuant to review and oversight by a Human Subjects Review Board in Midland, Michigan.

\section{REFERENCES}

[1] Alexander V, Leffingwell SS, Lloyd JW, Waxweiler RJ, Miller RL. Brain cancer in petrochemical workers: a case series report. Am J Ind Med 1980; 1(1): 115-23.

[2] Austin SG, Schnatter R. A case-control study of chemical exposures and brain tumors in petrochemical workers. J Occup Med 1983; 25(4): 313-20.

[3] Waxweiler RJ, Alexander V, Leffingwell SS, Haring M, Lloyd JW. Mortality from brain tumor and other causes in a cohort of petrochemical workers. J Natl Cancer Inst 1983; 70(1): 75-81.

[4] Leffingwell SS, Waxweiler R, Alexander V, Ludwig HR, Halperin W. Case-control study of gliomas of the brain among workers employed by a Texas City, Texas chemical plant. Neuroepidemiology 1983; 2: 179-95.

[5] Bond GG, Cook RR, Wight PC, Flores GH. A case-control study of brain tumor mortality at a Texas chemical plant. J Occup Med 1983; 25(5): 377-86.

[6] Wen CP, Tsai SP, Gibson RL. A report on brain tumors from a retrospective cohort study of refinery workers. Ann N Y Acad Sci 1982; 381:130-8.

[7] Bond GG, Cook RR, Shellenberger RJ, Daniel RL, Fishbeck WA Case-control study of brain tumor deaths among employees at a chemical manufacturing plant. Ann N Y Acad Sci 1982; 381: 7382.

[8] Reeve GR, Bond GG, Lloyd JW, Cook RR, Waxweiler RJ, Fishbeck WA. An investigation of brain tumors among chemical plant employees using a sample-based cohort method. J Occup Med 1983; 25(5): 387-93.

[9] Thomas TL, Waxweiler R, Crandall M, et al. Brain cancer among OCAW members in three Texas oil refineries. Ann N Y Acad Sci 1982; 381:120-9. 
[10] Teta MJ, Ott MG, Schnatter AR. An update of mortality due to brain neoplasms and other causes among employees of a petrochemical facility. J Occup Environ Med 1991; 33: 45-51.

[11] Marsh GM, Youk AO, Stone RA, Sefcik S, Alcorn C. OCMAPPLUS: A program for the comprehensive analysis of occupational cohort data. J Occup Environ Med 1998; 40: 351-62.

[12] Percy CL, Miller BA, Gloeckler L. Effect of changes in cancer classification and the accuracy of cancer death certificates on trends in cancer mortality. Ann N Y Acad Sci 1990; 609: 87-99.

[13] Greenwald P, Friedlander BR, Lawrence CE, Hearne T, Earle K. Diagnostic sensitivity bias - an epidemiologic explanation for an apparent brain tumor excess. J Occup Med 1981; 23(10): 690-4.
[14] Preston-Martin S, Munir R, Chakrabarti I. Nervous system. In: Schottenfeld D, Fraumeni Jr JF, Eds. Cancer Epidemiology and Prevention. Third ed. Oxford: University Press; 2006. pp. 1173-95.

[15] Beall C, Delzell E, Rodu B, Sathiakumar N, Myers S. Cancer and benign tumor incidence among employees in a polymer research complex. J Occup Environ Med 2001; 43: 914-24.

[16] Cooper SP, Labarthe D, Downs T, et al. Cancer mortality among petroleum refinery and chemical manufacturing workers in Texas. $\mathbf{J}$ Environ Pathol Toxicol Oncol 1997; 16(1): 1-14.

(C) Haidar et al.; Licensee Bentham Open.

This is an open access article distributed under the terms of the Creative Commons Attribution License (http://creativecommons.org/licenses/by/2.5/), which permits unrestrictive use, distribution, and reproduction in any medium, provided the original work is properly cited. 